http://ejournal.upi.edu/index.php/jaz - e-mail: jurnal.zonasi@gmail.com dan jurnal_zonasi@upi.edu doi.org/10.17509/jaz.v3i1.17892

\title{
KAWASAN WISATA WATERFRONT TANJUNG ADIKARTO KULON PROGO
}

Article History:
First draft received:
24 Juni 2019
Revised:
27 November 2019
Accepted:
10 Januari 2020
Final proof received:
Print:
25 Februari 2020
Online
29 Februari 2020

\author{
Azizah Nurul Muflihah ${ }^{1}$; Dita Ayu Rani Natalia ${ }^{2}$ \\ ${ }^{1,2}$ Universitas Teknologi Yogyakarta, Yogyakarta, Indonesia \\ Jalan Siliwangi, Jl. Ringroad Utara Jl. Jombor Lor, Mlati Krajan, Sendangadi, Kec. Mlati, \\ Kabupaten Sleman, Daerah Istimewa Yogyakarta 55285 \\ Email: ${ }^{1}$ azizahmuflihah27@gmail. \\ 2ditayurani@uty.ac.id
}

\begin{abstract}
Tourism is one of the biggest sectors in Yogyakarta. The increasing number of new tourist destinations has increased the number of tourists. Increasing visitors every year makes the Yogyakarta government make a policy about tourism, one of which is the development of tourism in the coastal area of Kulon Progo. Kulon Progo Regency is one of the tourist destinations that has many natural and culinary attractions. Downstream of the Serang river which is next to Tanjung Adikarto port in Karangwuni village, Wates has the potential as a tourist area with high natural resources and potential fish. The development of this area aims to empower the surrounding community with the main livelihood of the population are fishermen and traders. However, the surrounding community is less able to utilize its natural resources. Then the need for encouragement from the development of this region with the concept of community development. This approach aims to accommodate the economic needs of fishermen by designing fishing areas specifically for small fishermen on the Serang river and the food court used to process fish caught by fishermen to have a higher selling value. Support local traders and industries in Kulon Progo by designing souvenir centers so that local products can be marketed. This concept aims to increase the social status and economic status of the community. And can reduce the unemployment rate which is still quite high in Kulon Progo.
\end{abstract}

Keywords: community development; TanjungAdikarto; waterfront tourism.

Abstrak: Pariwisata merupakan salah satu sektor terbesar di Yogyakarta. Semakin banyaknya destinasi wisata baru membuat peningkatan jumlah wisatawan. Bertambahnya pengunjung setiap tahunnya membuat pemerintah Yogyakarta membuat kebijakan tentang pariwisata, salah satunya adalah pengembangan pariwisata di kawasan pesisir pantai Kulon Progo. Kabupaten Kulon Progo merupakan salah satu destinasi wisata yang memiliki banyak tempat wisata alam dan kuliner. Hilir sungai Serang yang berada disamping pelabuhan Tanjung Adikarto di desa Karangwuni, Wates memiliki potensi sebagai kawasan wisata dengan sumber daya alam dan potensi ikan yang cukup tinggi. Pembangunan kawasan ini bertujuan untuk memberdayakan masyarakat sekitar dengan mata pencaharian utama penduduk adalah nelayan dan pedagang. Namun masyarakat sekitar kurang mampu memanfaatkan sumber daya alam yang dimilikinya. Maka perlu adanya dorongan dari pembangunan kawasan ini dengan konsep community development. Pendekatan ini bertujuan untuk mewadahi kebutuhan perekonomian nelayan dengan merancang area pemancingan khusus nelayan kecil di sungai Serang dan foodcourt yang digunakan untuk mengolah ikan hasil tangkapan nelayan agar memiliki nilai jual lebih tinggi. Mendukung pedagang dan industri lokal yang terdapat di Kulon Progo dengan merancang pusat oleh-oleh sehingga produk lokal bisa dipasarkan. Konsep ini bertujuan untuk menaikkan status sosial dan status ekonomi masyarakat. Serta dapat mengurangi tingkat pengangguran yang masih cukup tinggi di Kulon Progo.

Kata Kunci: community development; Tanjung Adikarto; wisata waterfront. 


\section{Pendahuluan}

\subsection{Latar Belakang}

Yogyakarta merupakan kota yang memiliki keanekaragaman suku bangsa dan kebudayaan. Yogyakarta juga memiliki banyak potensi pariwisata yang sangat potensial untuk di kembangkan. Sektor pariwisata Yogyakarta sekarang ini dapat dirasakan semakin bertambah pesat dari tahun ke tahun dan menjadi sektor yang sangat strategis untuk menambah pendapatan masyarakat lokal. Sehingga perlu adanya perhatian yang sangat serius terhadap pengelolaan di sektor ini.

Kebudayaan dan keindahan alam merupakan aset berharga yang selama ini mampu menarik wisatawan nusantara maupun mancanegara untuk datang dan berkunjung menikmati keindahan alam maupun untuk mempelajari keanekaragaman budaya yang ada di Yogyakarta dan sekitarnya. Pariwisata sekarang ini telah menjadi kebutuhan bagi masyarakat di berbagai lapisan ukan hanya untuk kalangan tertentu saja, sehingga dalam penanganannya harus dilakukan dengan serius dan melibatkan pihak-pihak yang terkait. Selain itu untuk mencapai semua tujuan pengembanan pariwisata, harus diadakan promosi agar potensi dan daya tarik wisata dapat lebih dikenal dan mampu menggerakkan calon wisatawan untuk berkunjung dan menikmati tempat wisata.

Desa Karangwuni, Kecamatan Wates, Kulon Progo, Yogyakarta, merupakan salah satu desa yang memiliki potensi wisata. Desa Karangwuni memiliki luas wilayah 722,35 ha dengan jumlah penduduk 3.281 (2017). Desa Karangwuni memiliki tingkat kepadatan yang rendah dibanding dengan kelurahan yang lain. Faktor yang mempengaruhi tingkat kepadatan adalah kedatangan dan kepindahan yan dipicu factor ekonomi dalam mencari pekerjaan. Mata pencaharian utama penduduk Desa Karangwuni adalah nelayan dan pedagang.

Prinsip pengembangan desa/kampung wisata adalah sebagai salah satu produk wisata alternatif yang dapat memberikan dorongan bagi pembangunan kawasan yang berkelanjutan serta memiliki prinsip-prinsip pengelolaan (Bappeda, 2013) (Primadella dan Ikaputra, 2019). Seiring dengan perkembangannya, muncul konsep wisata berbasis masyarakat, yaitu konsep wisata yang menyuguhkan sumber daya alam wilayah dan budaya setempat yang memiliki nilai konservasi serta mampu meningkatkan pendapatan ekonomi bagi masyarakat.

\subsection{Community Development Sebagai Pendekatan}

Prinsip pengembangan desa/kampung wisata adalah sebagai salah satu produk wisata alternatif yang dapat memberikan dorongan bagi pembangunan kawasan yang berkelanjutan serta memiliki prinsip-prinsip pengelolaan (Bappeda, 2013). Seiring dengan perkembangannya, muncul konsep wisata berbasis masyarakat, yaitu konsep wisata yang menyuguhkan sumber daya alam wilayah dan budaya setempat yang memiliki nilai konservasi serta mampu meningkatkan pendapatan ekonomi bagi masyarakat.

Pemberdayaan menurut arti secara bahasa adaah proses, cara, perbuatan membuat berdaya, yaitu kemampuan untuk melakukan sesuatu atau kemampuan bertindak yang berupa akal, ikhtiar atau upaya (Depdiknas, 2003). Dalam beberapa kajian mengenai pembangunan komunitas, pemberdayaan masyarakat sering dimaknai kontribusi kepada perencanaan dan keputusan yang mempengaruhi komunitasnya (Foy, 1994). Pemberdayaan ini memiliki tujuan dua arah, yaitu melepaskan kemiskinan dan pengangguran dan memperkuat posisi lapisan masyarakat dalam struktur kekuasaan. Pemberdayaan adalah sebuah proses dan tujuan. Sebagai tujuan, maka pemberdayaan adalah serangkaian kegiatan untuk memperkuat kekuasaan atau keberdayaan kelompok lemah dalam masyarakat, termasuk individu-indivdu yang mengalami masalah kemiskinan. Sebagai tujuan, maka pemberdayaan merujuk pada keadaan atau hasil yang ingin dicapai oleh sebuah perubahan sosial, yaitu masyarakat yang berdaya, memiliki kekuasaan atau mempunyai pengetahuan da kemampuan dalam memenuhi kebutuhan hidupnya baik yang bersfiat fisik, ekonomi maupun sosial seperti memiliki kepercayaan diri, mampu menyampaikan aspirasi, mempunyai mata pencaharian, berpartisipasi dalam kegiatan sosial, dan mandiri dalam melaksanakan tugas-tugas kehidupannya (Sipahelut, 2010).

Lapangan pekerjaan yang rendah berdampak pada tingkat pengangguran yang tinggi dan menjadi salah satu masalah sosial yang terdapat di Kulon Progo dengan mayoritas penduduk berprofesi sebagai nelayan dan pedagang. Namun masih banyak nelayan kecil yang kesulitan menangkap ikan di lautan lepas dikarenakan cuaca maupun alat berlayar, serta produsen industri lokal yang memasarkan produknya karena kurangnya wadah untuk memasarkan. Lokasi site berada disamping hilir sungai Serang dengan potensi ikan yang cukup tinggi, namun tidak ada nelayan yang memancing ditempat ini.

Perlunya penanganan masalah-masalah tersebut untuk mewadahi nelayan kecil dan industri lokal tersebut. Community development atau pemberdayaan masyarakat adalah konsep yang bertujuan untuk mewadahi dan meningkatkan kegiatan perekonomian dan sosial masyarakat setempat. 


\subsection{Wisata Waterfront}

Wisata adalah suatu kegiatan perjalanan yang dilakukan manusia baik perorangan maupun kelompok untuk mengunjungi destinasi tertentu dengan tujuan rekreasi, mempelajari keunikan daerah wisata, pengembangan diri dan sebagainya dalam kurun waktu yang singkat atau sementara waktu. (Sumber: UU RI no. 10 th 2009). Waterfront dalam bahasa Indonesia secara harfiah berarti daerah tepi laut atau sungai, bagian suatu wilayah yang berbatasan dengan air, daerah pelabuhan (Echols dalam Rahmat, 2006:2).

Lokasi site berada disamping sungai Serang dengan view taman bunga matahari di sebrang sungai dan laut Selatan di sisi Selatan site. Site dikembangan menjadi kawasan wisata yang menyediakan beberapa fasilitas wisata. Yaitu kuliner hasil ikan tangkapan nelayan dari sungai Serang, pusat souvenir yang menjual hasil industri kreatif lokal, serta wisata alam untuk berbagai kalangan.

\subsection{Isu Tentang Usulan}

Pariwisata merupakan sektor utama bagi DIY. Seiring dengan peran sektor pariwisata sebagai salah satu sektor penggerak ekonomi di DIY, dapat dikatakan bahwa industri pariwisata DIY saat ini memiliki prospek yang baik dan memiliki daya tarik yang kompetitif. Komitmen dan konsistensi pembangunan pariwisata DIY yang berkelanjutan dalam rangka meningkatkan kesejahteraan masyarakat maka penerapannya dititik beratkan pada strategi pengembangan destinasi, pengembangan pemasaran dan pengembangan pemasaran, pengembangan kemitraan, ketataruangan, aksesibilitas, SDM, kelembagaan, investasi dan pemberdayaan masyarakat.

Keputusan Menteri Kelautan dan Perikanan RI, Nomor KEP.39/MEN/2011 Tentang Perubahan Atas Keputusan Menteri Kelautan dan Perikanan Nomor KEP.32/MEN/2010 tentang Penetapan Kawasan Minapolitan menyebutkan bahwa Kulon Progo merupakan salah satu kawasan Minapolitan dari 5 kawasan yang terdapat di DIY.

Selain itu, terdapat kebijakan pemerintah untuk kawasan pesisir dan pulau-pulau kecil, yaitu kebijakan pengembangan kawasa pesisir dan pulau-pulau kecil meliputi pengembangan pariwisata, pemanfaatan dan pengelolaan potensi laut. Arahan penetapan kawasan peisisir dan pulau-pulau kecil di DIY, yaitu:

a. Kawasan pesisir meliputi pantai di Kabupaten Bantul, Kulon Progo, dan Gunung Kidul.

b. Kawasan pulau-pulau kecil di Kabupaten Gunung Kidul.

Pelabuhan Tanjung Adikarto di Desa Karangwuni, Wates, selain sebagai tempat pendaratan ikan, juga akan dijadikan pelabuhan wisata. Pengembangan wisata dapat memungkinkan untuk memberdayakan ekonomi kerakyatan dan menyumbang pemasukan bagi daerah. Pelabuhan Tanjung Adikarto memiliki potensi yang dapat dikembangkan menjadi objek wisata. Lokasinya yang strategis mampu bersaing dengan Pantai Glagah. Pelabuhan juga bisa menjadi pusat penelitian bahari yang bekerjasama dengan perguruan tinggi. Hal tersebut di dukung oleh alokasi dana dari APBN dan APBD yang sangat memungkinkan untuk menyokong pengembangan wisata Kulon Progo. (Sumber: Kuat Tri Utama sebagai Kasi Objek Wisata dan Sarana Pariwisata Disparpora Kulon Progo dalam Radar Jogja 3 Januari 2017).

\subsection{Rumusan Masalah}

\section{Permasalahan Umum:}

Bagaimana merancang kawasan wisata waterfront Tanjung Adikarto di desa Karangwuni, Kulon Progo, dengan alam dan kuliner yang menjadi salah satu potensi?

\section{Permasalahan Khusus:}

Bagaimana menerapkan konsep community development di kawasan wisata waterfront Tanjung Adikarto yang dapat mewadahi kebutuhan perekonomian nelayan, pedagang dan industri lokal yang terdapat di Kulon Progo khususnya penduduk desa Karangwuni sehingga dapat membangun dan meningkatkan status sosial dan ekonomi masyarakat sekitar?

\subsection{Tujuan dan Sasaran}

\section{Tujuan}

Merancang kawasan wisata waterfront Tanjung Adikarto yang dapat meningkatkan perekonomian masyarakat sekitar. 


\section{Sasaran}

Adapun sasaran yang ingin dicapai adalah:

a. Menerapkan konsep community development pada perancangan kawasan wisata waterfront Tanjung Adikarto.

b. Merancang fasilitas yang dapat mewadahi kebutuhan perekonomian masyarakat sehingga dapat meningkatkan status ekonomi dan sosial masyarakat.

c. Merancang fasilitas wisata berdasarkan potensi yang ada.

d. Menghasilkan landasan-landasan konseptual perancangan kawasan wisata waterfront Tanjung Adikarto yang akan dijadikan dasar dalam transformasi desain ke dalam bentuk gambar rencana.

\section{Tinjauan Pustaka}

\subsection{Perancangan}

Perancangan adalah suatu kegiatan yang memiliki tujuan untuk mendesign sistem baru yang dapat menyelesaikan masalah-masalah yang dihadapi yang diperoleh dari pemilihan alternatif sistem yang terbaik. (Al-Bahra bin Ladjamudin, 2005:39)

\subsection{Wisata}

Wisata adalah suatu kegiatan perjalanan yang dilakukan manusia baik perorangan maupun kelompok untuk mengunjungi destinasi tertentu dengan tujuan rekreasi, mempelajari keunikan daerah wisata, pengembangan diri dan sebagainya dalam kurun waktu yang singkat atau sementara waktu. (Sumber: UU RI no. 10 th 2009).

\subsection{Waterfront}

Waterfront dalam Bahasa Indonesia secara harfiah berarti daerah tepi laut, bagian suatu wilayah yang berbatasan dengan air, daerah pelabuhan. (Echols dalam Rahman,2006:2).

\subsection{Community Development}

Pemberdayaan ini memiliki tujuan dua arah, yaitu melepaskan kemiskinan dan pengangguran dan memperkuat posisi lapisan masyarakat dalam struktur kekuasaan. Pemberdayaan adalah sebuah proses dan tujuan. Sebagai tujuan, maka pemberdayaan adalah serangkaian kegiatan untuk memperkuat kekuasaan atau keberdayaan kelompok lemah dalam masyarakat, termasuk individu-indivdu yang mengalami masalah kemiskinan. Sebagai tujuan, maka pemberdayaan merujuk pada keadaan atau hasil yang ingin dicapai oleh sebuah perubahan sosial, yaitu masyarakat yang berdaya, memiliki kekuasaan atau mempunyai pengetahuan da kemampuan dalam memenuhi kebutuhan hidupnya baik yang bersfiat fisik, ekonomi maupun sosial seperti memiliki kepercayaan diri, mampu menyampaikan aspirasi, mempunyai mata pencaharian, berpartisipasi dalam kegiatan sosial, dan mandiri dalam melaksanakan tugas-tugas kehidupannya (Sipahelut, 2010).

Kesimpulan dari pengertian judul Perancangan Kawasan Wisata Waterfront Tanjung Adikarto dengan Pendekatan Community Development diatas adalah bahwa perencanaan kawasan wisata waterfront Tanjung Adikarto di kawasan Minapolitan dengan pendekatan community development merupakan perencanaan sebuah kawasan wisata di tepi sungai yang berada di kawasan Pelabuhan Tanjung Adikarto dengan konsepsi pembangunan ekonomi kemasyarakatan guna mencapai kondisi sosial ekonomi dan kualitas kehidupan yang lebih baik.

\section{Metode Perancangan}

Metode perancangan merupakan rangkaian atau langkah-langkah cara berpikir dalam sebuah perancangan dalam studi arsitektur, yang dilakukan secara berurutan mulai dari penggalian ide perancangan, setelah itu meninjau dan mengidentifikasi permasalahan terkait perancangan kawasan wisata waterfront Tanjung Adikarto dengan pendekatan community development yang mungkin dapat diselesaikan dengan cara arsitektural. Semua hal itu akan dirangkum dalam rumusan masalah. Dalam pembahasan berikutnya perlu adanya langkah-langkah dalam pencarian data primer maupun sekunder yang berkaitan dengan kawasan wisata waterfront Tanjung Adikarto. Beberapa langkah tahapan perancangan yang digunakan untuk mencapai sebuah tujuan diantaranya pengumpulan data, analisis, sintesis atau konsep rancangan setelah itu riset terkait community development yang semua itu terangkum dalam sistematika berfikir dalam studi arsitektur. 
Metode perancangan yang digunakan dalam Perencanaan Pengembangan Kawasan Wisata Waterfront Tanjung Adikarto dengan Pendekatan Community Development menggunakan penelitian dengan metode analisis. Metode perancangan bersifat kualitatif, yaitu dengan mengumpulkan data-data yang berupa rincian data yang dicari seperti, wawancara, studi literatur dan hasil survey yang mana diuraikan dengan apa adanya sesuai dengan data tersebut.

\subsection{Lingkup Pembahasan}

\subsubsection{Lingkup Arsitektural}

Pembangunan dalam suatu kawasan perlu memperhatikan aspek-aspek yang berlaku dalam pengolahan ruang dan penataan lahan agar pembangunan sesuai dengan standard yang telah ditetapkan, salah satu diantara aspek Arsitektural antara lain:

a. Analisis tapak kawasan samping sungai Serang, desa Karangwuni, Wates, Kulon Progo, DI. Yogyakarta.

b. Program ruang dan kebutuhan ruang untuk kawasan wisata waterfront yang meliputi restoran, pusat souvenir oleh-oleh, kantor pengelola dan fasilitas wisata outdoor dan taman.

c. Studi literatur tentang kawasan wisata waterfront dan konsep community development.

d. Konsep community development yang digunakan dalam metode perancangan.

\subsubsection{Lingkup Non-Arsitektural}

a. Pengertian kawasan wisata waterfront secara umum.

b. Kajian tentang konsep Community Development sebagai konsep perancangan.

c. Fasilitas penunjang dan pelengkap kawasan wisata waterfront Tanjung Adikarto.

\subsection{Metode Pendekatan Desain}

\subsubsection{Perancangan}

Dalam melakukan proses perancangan perlu mempertimbangkan dan menggali fasilitas dan fungsi apa yang akan dirancang untuk mencapai tujuan dan sasaran. Seperti kebutuhan ruang, fasilitas penunjang dan pendukung yang diperlukan dalam perancangan, serta menggali potensi yang ada dan memanfaatkannya dalam proses perancangan. Dalam melakukan perancangan ada sebuah masalah yang menjadi bahan acuan.

Pada kasus ini, perancangan dilakukan karena lokasi site memiliki potensi sebagai kawasan wisata yang dapat bersaing dan menjadi salah satu destinasi wisata yang ada di Kulon Progo. Selain itu, terdapat kebijakan pemerintah untuk kawasan pesisir dan pulau-pulau kecil, yaitu kebijakan pengembangan kawasa pesisir dan pulau-pulau kecil meliputi pengembangan pariwisata, pemanfaatan dan pengelolaan potensi laut. Arahan penetapan kawasan peisisir dan pulau-pulau kecil di DIY, salah satunya adalah kawasan pesisir pantai Kulon Progo.

\subsubsection{Pendekatan Konsep Perancangan}

Pada tugas akhir ini penulis melakukan penerapan konsep dengan beberapa metode, yaitu dengan mengalisis lokasi site dan kawasan sekitarnya, menggali potensi yang ada dan dapat dikembangan, serta mengalisis kebutuhan yang menjadi wadah perekonomian masyarakat sekitar yang dapat diterapkan, dengan beberapa ide atau gagasan digunakan sebagai konsep dasar pemecahan masalah terhadap perancangan kawasa wisata waterfront Tanjung Adikarto.

Dari tahap alternatif masing-masing analisis akan di ambil solusi terpilih untuk digabungkan dengan solusi perancangan pada analisa yang lainnya. Hasilnya sebagai konsep dasar perancangan. 


\subsection{Alur Pola Pikir}

\section{Latar Belakang}

- Penjelasan Batasan Judul

- Latar Belakang Lokasi

\section{LATAR BELAKANG PERMASALAHAN}

- Lokasi Kulon Progo yang berpotensi menjadi kawasan wisata.

- Perkembangan jumlah wisatawan yang terus bertambah setiap tahun di Kulon Progo.

- Pariwisata merupakan sektor utama DIY.

- Kebijakan pemerintah tentang pengembangan kawasan pesisir Kulon Progo.

\section{RUMUSAN MASALAH}

- Bagaimana merancang kawasan wisata waterfront Tanjung Adikarto di desa Karangwuni, Kulon Progo, dengan alam dan kuliner yang menjadi salah satu potensi?

- Bagaimana menerapkan konsep community development di kawasan wisata waterfront Tanjung Adikarto yang dapat mewadahi kebutuhan perekonomian nelayan, pedagang dan industri lokal yang terdapat di Kulon Progo khususnya penduduk desa Karangwuni sehingga dapat membangun dan meningkatkan status sosial dan ekonomi masyarakat sekitar?

\section{TUJUAN DAN SASARAN}

Merancang kawasan wisata waterfront Tanjung Adikarto yang dapat meningkatkan perekonomian masyarakat sekitar.

Adapun sasaran yang ingin dicapai adalah:

- Menerapkan konsep community development pada perancangan kawasan wisata waterfront Tanjung Adikarto.

- Merancang fasilitas yang dapat mewadahi kebutuhan perekonomian masyarakat sehingga dapat meningkatkan status ekonomi dan sosial masyarakat.

- Merancang fasilitas wisata berdasarkan potensi yang ada.

- Menghasilkan landasan-landasan konseptual perancangan kawasan wisata waterfront Tanjung Adikarto yang akan dijadikan dasar dalam transformasi desain ke dalam bentuk gambar rencana.

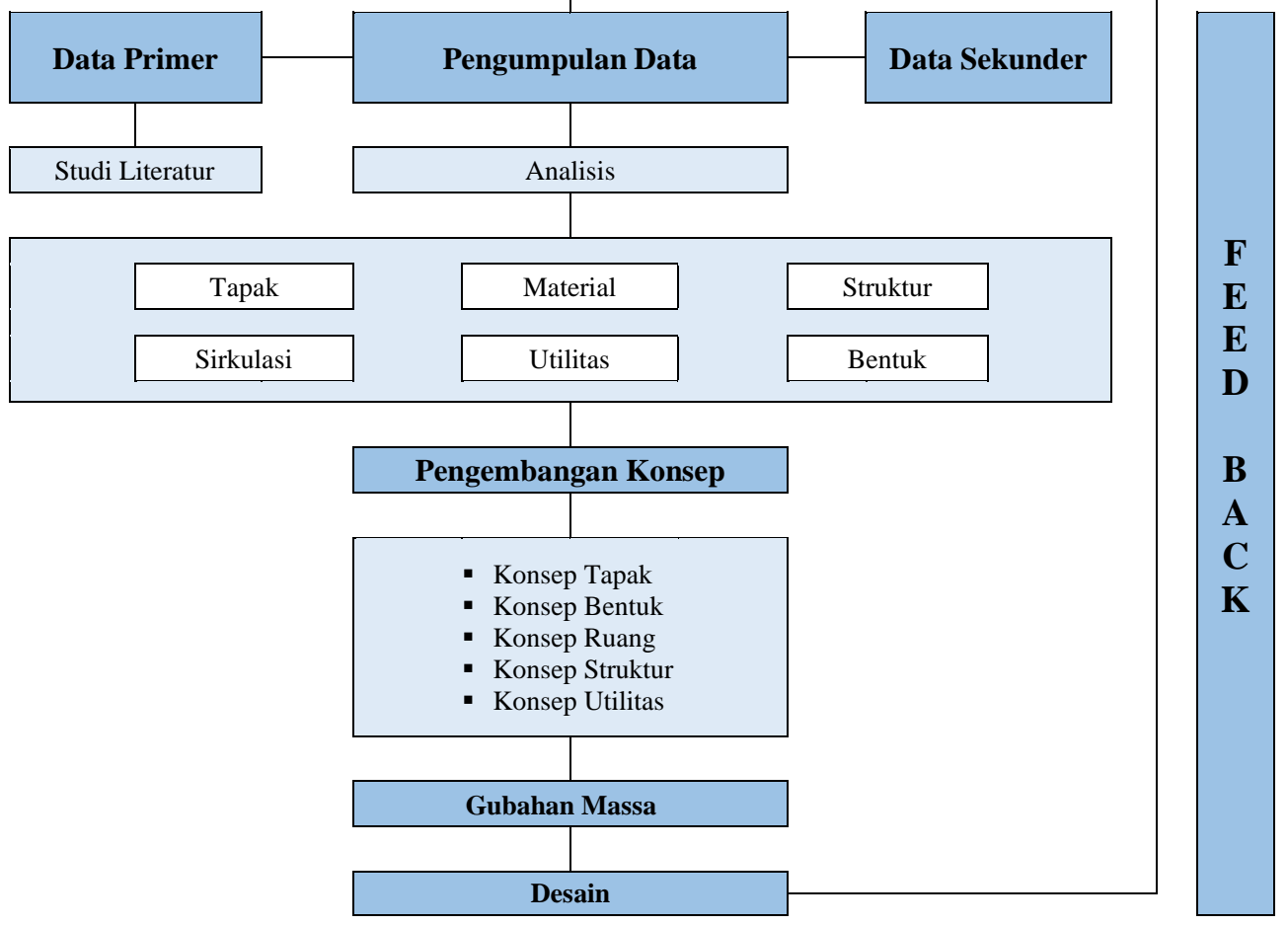

Gambar 1. Diagram Alur Pola Pikir

Sumber: Analisis Penulis, 2019 


\section{Hasil Pembahasan}

\subsection{Lokasi Site}

Lokasi site berada di jalan Glagah, Keboan, Glagah yang berada di desa Karangwuni, Wates. Berada di pesisir pantai selatan.

Desa Karangwuni, kecamatan Wates, Kulon Progo, Yogyakarta, merupakan salah desa yang memiliki potesi wisata. Desa Karangwuni memiliki luas wilayah 722,35 ha dengan jumlah penduduk laki laki berjumlah 1625 dan penduduk perempuan berjumlah 1656. Desa Karangwuni memiliki tingkat kepadatan yang rendah dibandingkan dengan kelurahan yang lain. Faktor yang mempengaruhi tingkat kepadatan adalah kedatangan dan kepindahan yang dipicu faktor ekonomi dalam mencari pekerjaan. Mata pencaharian utama penduduk Desa Karangwuni adalah nelayan dan pedagang.

\subsection{Analisis Site}

\subsubsection{Aksesibilitas}

\section{Analisis}

Jalan kawasan hanya terdapat disisi Timur site. Menggunakan akses dua jalur yang dipisahkan oleh median jalan dan terdapat jalur putar di tengah dan ujung site.

\section{Respon}

Akses keluar masuk dibagi menjadi 2. Yaitu ditengah sebagai main gate untuk pengunjung dan pengelola, dan di Utara main gate untuk karyawan dan keperluan distribusi.

\subsubsection{Matahari}

\section{Analisis}

Seluruh area site mendapat sinar matahari sepanjang hari. Namun kurangnya vegetasi dan peneduh dapat mengakibatkan overlighting.

\section{Respon}

Menambah vegetasi di dalam site sebagai peneduh di luar ruangan. Bukaan bangunan di sisi Barat dengan tritisan dan peneduh di depan bukaan.

\subsubsection{Kebisingan}

\section{Analisis}

Tingkat kebisingan cukup tinggi di sisi Timur karena merupakan sirkulasi utama, sedangkan tingkat kebisingan rendah di sisi Barat.

\section{Respon}

Pohon digunakan sebagai pengahalang $\mathrm{CO}_{2}$ agar tidak terjadi polusi udara di area kawasan wisata yang berasal dari parkiran. Sisi Selatan digunakan sebagai area parkir dan area titik kumpul.

\subsubsection{Angin}

\section{Analisis}

Angin dari Selatan cukup kencang dan membawa uap air dengan konsentrasi garam cukup tinggi.

\section{Respon}

Penggunaaan material beton dengan campuran semen tipe V (Sulfate Resistence Cement). Posisi bangunan memanjang dan tidak masive untuk meminimalisir beban horizontal pada bangunan.

\subsubsection{Hujan}

\section{Analisis}

Mendapatkan hujan sepanjang tahun karena berada di iklim tropis. Potensi terjadinya air menggenang dan tampias hujan pada bangunan saat intensitas hujan tinggi di bulan-bulan tertentu.

\section{Respon}

- Penggunaan paving block pada pedestrian agar bisa dilalui oleh pengunjung saat hujan.

- Membuat saluran drainase yang bertujuan untuk mengurangi genangan air hujan di dalam site.

\subsubsection{Orientasi View}

\section{Analisis}

- Jalan kawasan di sepanjang sisi Timur site dengan kedaraan yang berlalu lalang.

\section{Respon}

- Semua bukaan pada bangunan di arahkan ke sisi Barat.

- Gazebo di samping sungai sebagai tempat bersantai. 
- Sungai di sepanjang sisi Barat site dengan taman buatan

- Sirkulasi keluar masuk kapal ikan menuju dermaga pelabuhan.
- Bangunan memanjang untuk menghalangi view ke sisi Timur.

- Gardu pandang dengan tinggi $2.5 \mathrm{~m}$ dengan sirkulasi sky deck agar dapat melihat seluruh site dari ketinggian

\subsubsection{Infrstruktur}

\section{Analisis}

- Terdapat sumber energi listrik menuju pelabuhan yang dapat digunakan sebagai sumber energi utama di dalam site.

- Terdapat saluran drainase di sepanjang sisi Timur site.

- Sumber listrik hanya melewati site karena pemenuhan infrastruktur hanya di area pelabuhan.

\section{Respon}

- Membuat saluran elektrikal masuk ke dalam site sebagai sumber listrik utama dan genset sebagai sumber energi sekunder.

- Saluran drainase diarahkan menuju sungai Serang melalui site.

\subsubsection{Kondisi Tepian Sungai}

\section{Analisis}

- Kondisi sungai yang tenang tanpa ombak namun memiliki kedalaman hingga 8 meter sehingga tidak aman untuk dijadikan wisata air bagi anak-anak.

- Terdapat banyak ikan yang dapat dipancing oleh wisatawan dan nelayan kecil untuk diolah dan dijual.

\section{Respon}

- Membuat pintu air untuk mengatur debit air di dalam danau buatan.

- Membuat danau buatan dengan kedalaman 2,5 m yang aman untuk wisata air.

- Promenade di sisi sungai dan bisa digunakan untuk tempat memancing para pengunjung.

\subsection{Program Ruang}

\subsubsection{Analisis Pengguna}

Tabel 1. Analisis Pengguna

\begin{tabular}{|c|l|l|}
\hline No. & Kelompok Pengguna & \multicolumn{1}{|c|}{ Keterangan } \\
\hline 1. & Pengunjung & $\begin{array}{l}\text { - Pengunjung umum } \\
\text { - Pembeli }\end{array}$ \\
\hline 2. & Pedagang \& Jasa & $\begin{array}{l}\text { - Nelayan kecil } \\
\text { - Pedagang } \\
\text { - Karyawan foodcourt } \\
\text { - Buruh dagang }\end{array}$ \\
\hline 3. & Pengelola & $\begin{array}{l}\text { - Kepala pengelola } \\
\text { - Operasional }\end{array}$ \\
\hline 4. & Distributor & $\begin{array}{l}\text { - Administrasi } \\
\text { - Keamanan kawasan }\end{array}$ \\
\hline
\end{tabular}

Sumber: Analisis Penulis, 2019

\subsubsection{Kebutuhan Ruang}

Tabel 2. Kebutuhan Ruang

\begin{tabular}{|c|l|c|c|c|c|}
\hline No. & \multicolumn{1}{|c|}{ Nama Ruang } & Kapasitas & Jumlah & Luas Total & Jumlah Total \\
\hline 1. & Gazebo & 6 & 9 & $144 \mathrm{~m}^{2}$ & \\
2. & Foodcourt & 180 & 1 & $416 \mathrm{~m}^{2}$ & \\
3. & Pusat oleh-oleh & 50 & 1 & $384 \mathrm{~m}^{2}$ & \\
4. & Gardu pandang & 6 & 7 & $16 \mathrm{~m}^{2}$ & \\
5. & Camping ground & 40 & 1 & $358 \mathrm{~m}^{2}$ & \\
6. & Amphitheater & 20 & 1 & $180 \mathrm{~m}^{2}$ & $\mathbf{3 . 8 0 9} \mathbf{~ m}^{\mathbf{2}}$ \\
\hline
\end{tabular}




\begin{tabular}{|c|l|c|c|c|c|}
\hline No. & \multicolumn{1}{|c|}{ Nama Ruang } & Kapasitas & Jumlah & Luas Total & Jumlah Total \\
\hline 7. & Kios & 2 & 10 & $80 \mathrm{~m}^{2}$ & \\
8. & Temporary market & 50 & 1 & $200 \mathrm{~m}^{2}$ & \\
9. & Lobi & 10 & 1 & $48 \mathrm{~m}^{2}$ & \\
10. & Ruang manager & 2 & 1 & $17 \mathrm{~m}^{2}$ & \\
11. & Ruang bendahara & 2 & 1 & $17 \mathrm{~m}^{2}$ & \\
12. & Ruang staff & 2 & 6 & $102 \mathrm{~m}^{2}$ & \\
13. & Ruang rapat & 8 & 1 & $17 \mathrm{~m}^{2}$ & \\
14. & Ruang serba guna & 8 & 1 & $17 \mathrm{~m}^{2}$ & \\
15. & Ruang karyawan & 8 & 4 & $68 \mathrm{~m}^{2}$ & \\
16. & Ruang ME & 2 & 2 & $10 \mathrm{~m}^{2}$ & \\
17. & Lavatory & 1 & 24 & $54 \mathrm{~m}^{2}$ & \\
18. & Janitor & 2 & 3 & $24 \mathrm{~m}^{2}$ & \\
19. & Gudang & 2 & 3 & $48 \mathrm{~m}^{2}$ & \\
20. & Mushola & 8 & 1 & $17 \mathrm{~m}^{2}$ & \\
21. & Parkir motor & 1 & 220 & $440 \mathrm{~m}^{2}$ & \\
22. & Parkir mobil & 1 & 40 & $700 \mathrm{~m}^{2}$ & \\
23. & Parkir bus & 1 & 7 & $420 \mathrm{~m}^{2}$ & \\
\hline
\end{tabular}

Sumber: Analisis Penulis, 2019

\subsection{Konsep Tematik}

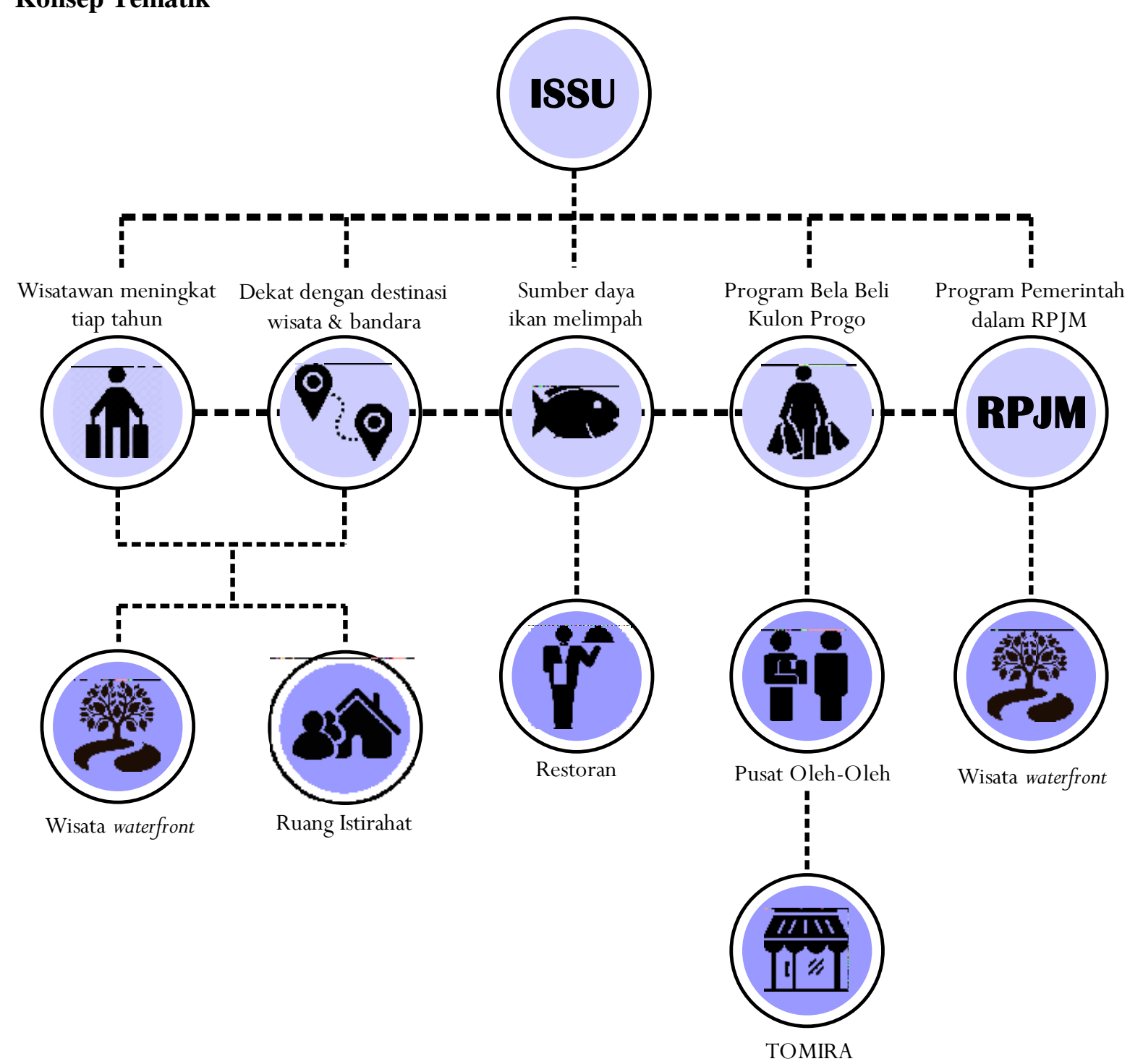




\subsection{Pengembangan Desain}

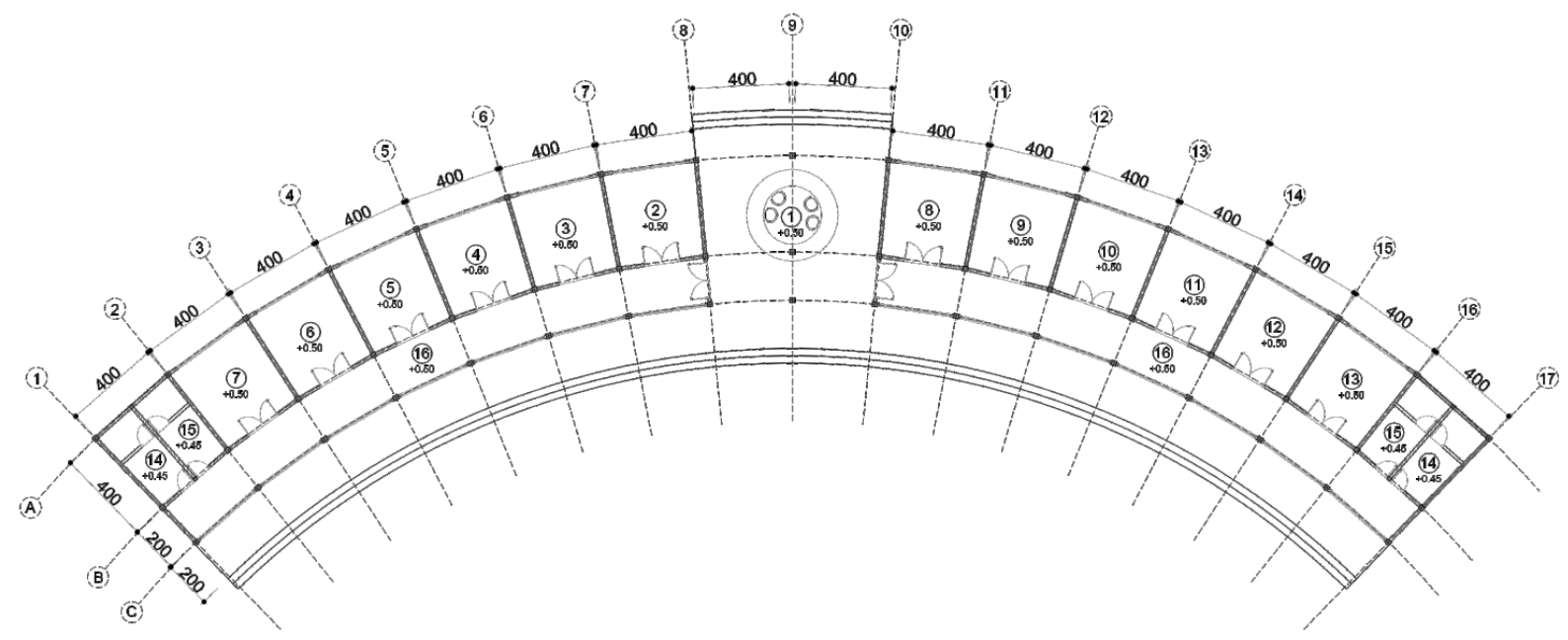

Gambar 2. Denah Gedung Pengelola

Sumber: Penulis, 2019

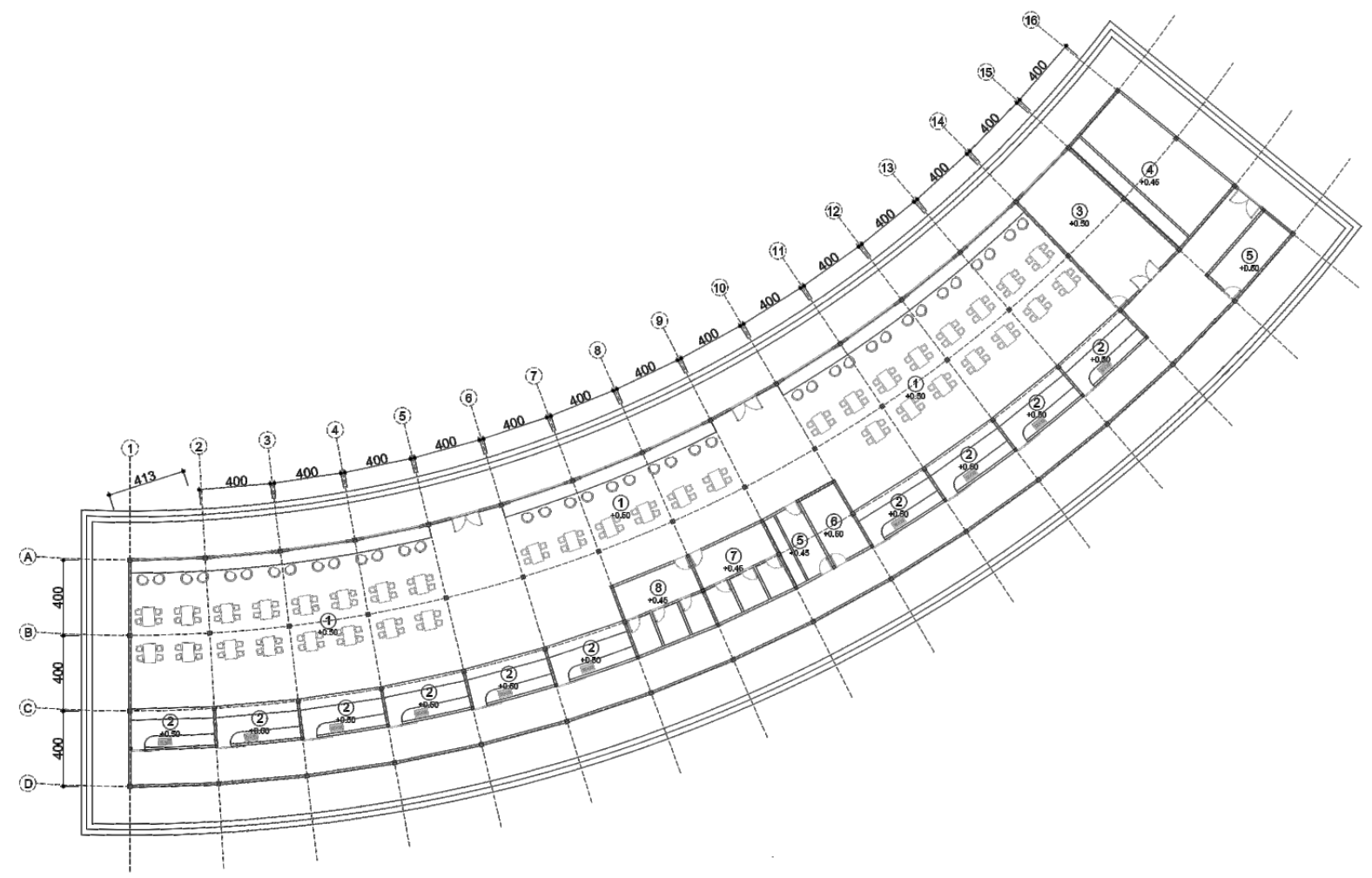

Gambar 3. Denah Foodcourt

Sumber: Penulis, 2019 


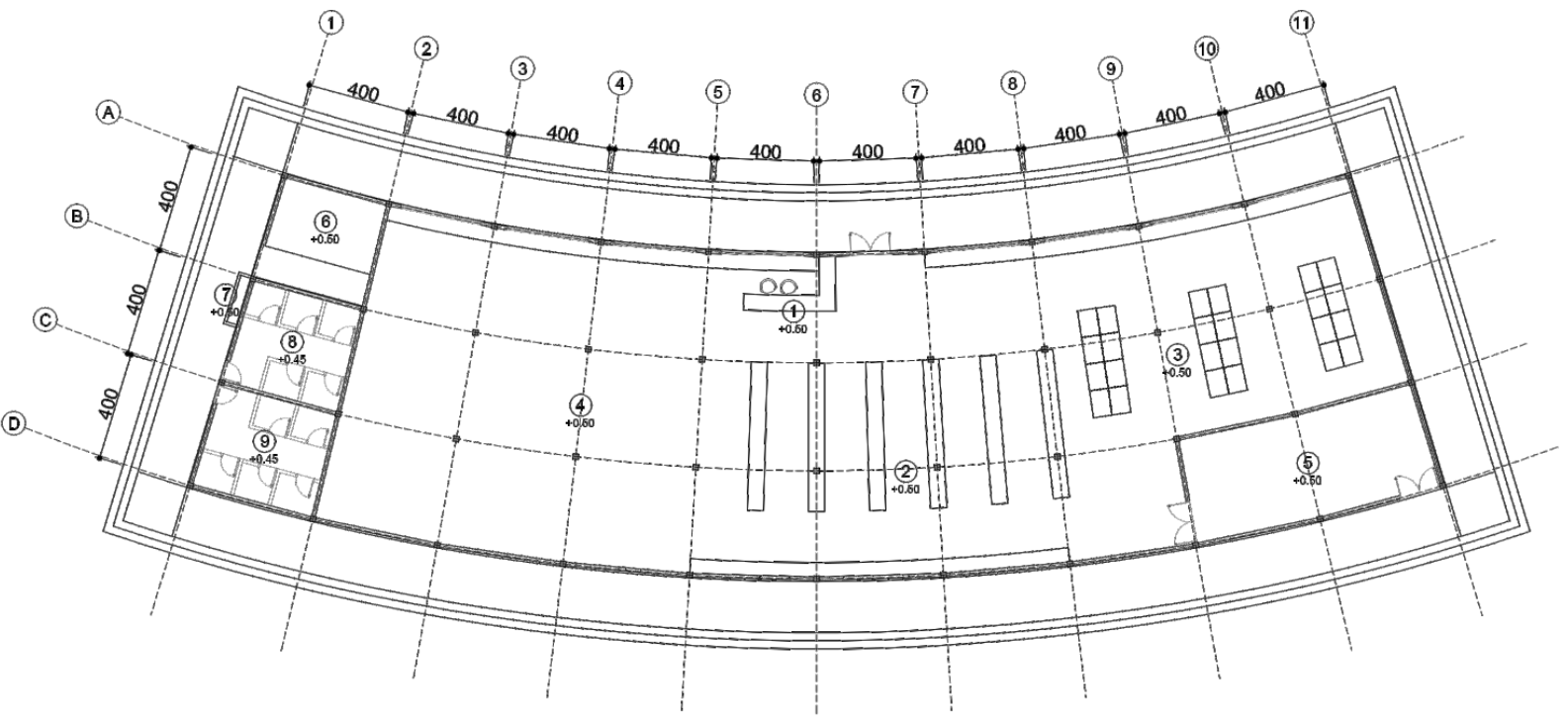

Gambar 4. Denah Pusat Oleh-Oleh

Sumber: Penulis, 2019

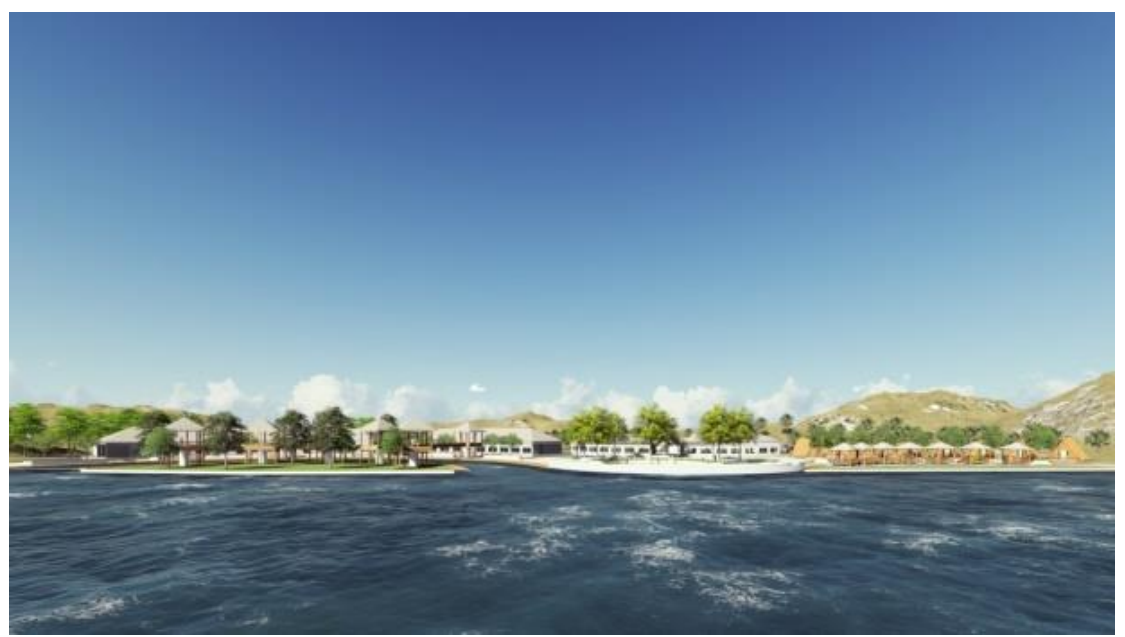

Gambar 5. Tampak Barat Kawasan

Sumber: Penulis, 2019

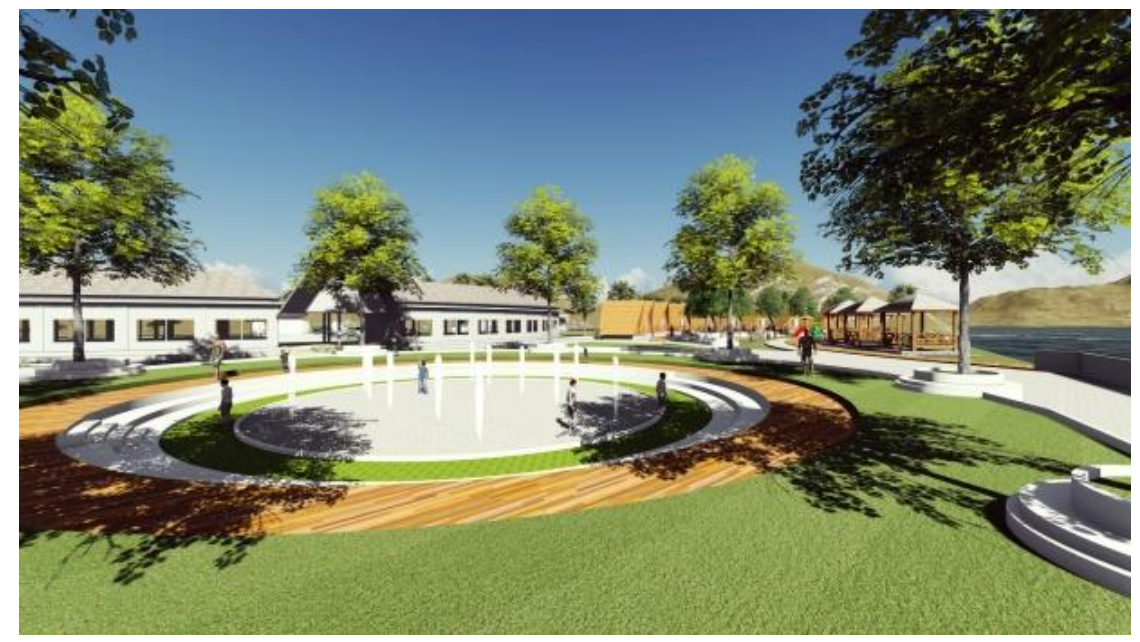

Gambar 15. Perspektif Mata Normal

Sumber: Penulis, 2019 


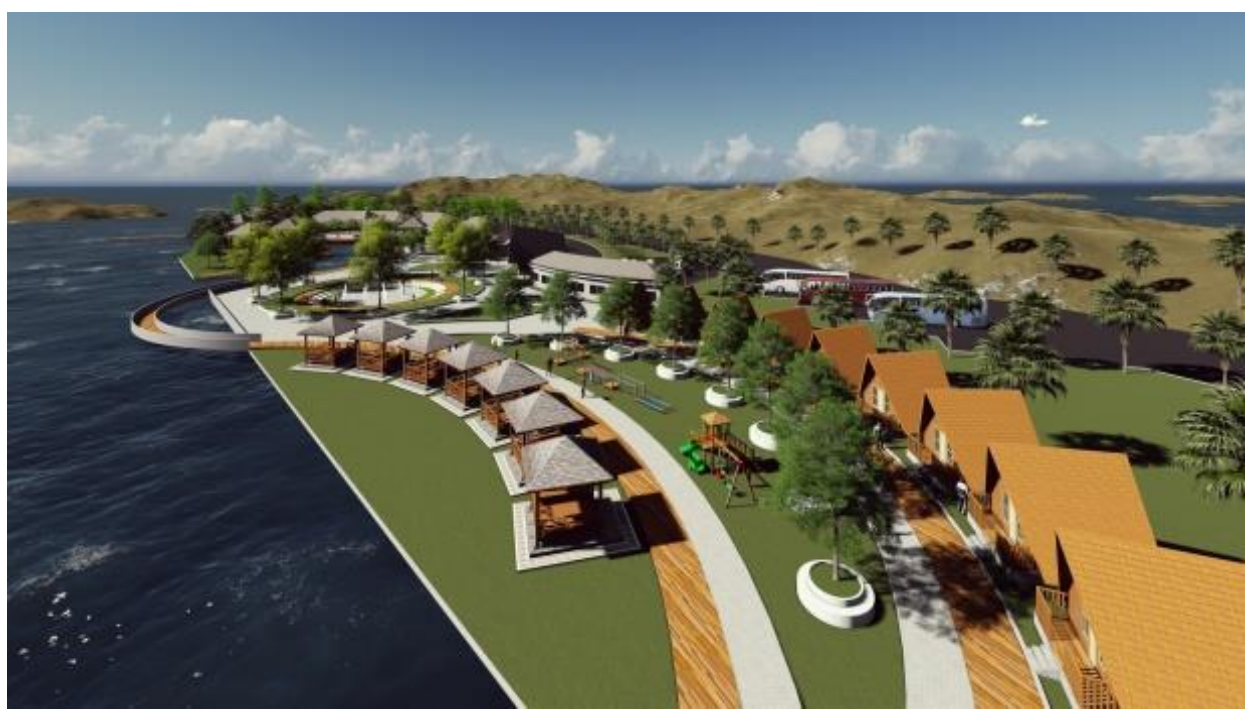

Gambar 16. Perspektif Mata Burung

Sumber: Penulis, 2019

\section{Kesimpulan}

Perancangan kawasan wisata waterfront Tanjung Adikarto ini bertujuan untuk menggali dan memanfaatkan potensi yang ada di lokasi site dan sekitarnya sehingga dapat menjadi salah satu destinasi wisata di Kulon Progo. Sedangkan pendekatan yang di terapkan pada perancangan ini bertujuan untuk mewadahi kebutuhan perekonomian nelayan dengan merancang area pemancingan khusus nelayan kecil di sungai Serang yang memiliki potensi ikan cukup tinggi dan foodcourt yang digunakan untuk mengolah ikan hasil tangkapan nelayan agar memiliki nilai jual lebih tinggi, juga pedagang dan industri lokal yang terdapat di Kulon Progo khususnya penduduk desa Karangwuni dengan merancang pusat oleh-oleh sehingga produk lokal bisa dipasarkan. Sehingga dapat membangun dan meningkatkan status sosial dan ekonomi masyarakat sekitar. Selain itu, juga membuka lapang pekerjaan sehingga dapat mengurangi tingkat pengangguran di Kulon Progo yang masuk cukup tinggi.

\section{Ucapan Terima Kasih}

Puji syukur penulis panjatkan kepada Tuhan Yang Maha Esa, karena atas berkat dan rahmat-Nya, penulis dapat menyelesaikan tugas akhir ini yang terdiri dari gagasan konsep dan pengembangan desain yang dilakukan untuk memenuhi salah satu syarat pencapaian gelar Sarjana Arsitektur pada Program Studi Arsitektur, Fakultas Sains dan Teknologi, Universitas Teknologi Yogyakarta.

Penulis menyadari bahwa, banyak bantuan dan bimbingan telah penulis terima dari berbagai pihak, dari masa perkuliahan sampai pada penyusunan tugas akhir ini. Oleh karena itu, penulis mengucapkan terima kasih kepada:

a. Ibu Dita Ayu Rani Natalia. S.T., M.Sc selaku Dosen Pembimbing Ketua Program Studi Arsitektur, yang selalu memberi semangat dalam penyelesaian studi dan telah menyediakan waktu, tenaga dan pikiran untuk mengarahkan penulis dalam penyusunan tugas akhir ini;

b. Pihak Dinas Pariwisata, Dinas Kelautan dan Bappeda Kota Yogyakarta yang telah banyak membantu dalam usaha memperoleh data yang penulis perlukan;

c. Orang tua dan keluarga penulis yang telah memberikan bantuan dukungan material dan moral; dan

d. Sahabat yang telah banyak membantu penulis dalam menyelesaikan tugas akhir ini.

\section{Referensi}

Ching, Francis D.K. 2000. Arsitektur, Bentuk, Ruang Dan Susunannya. Jakarta. Erlangga. Depdiknas. 2003. Kamus Besar Bahasa Indonesia, Edisi Ketiga, Jakarta: Penerbit Balai Pustaka. Foy, Nancy. 1994. Empowering People at Work, London: Grower Publishing Company.

Jimu, M.I. 2008. Community Development. Community Development:A Cross-Examination of Theory and

Practice Using Experiences in Rural Malawi. Africa Development, Vol. XXXIII, No. 2, 2008, pp. 23-3.

KEP.39/MEN/2011 Tentang Perubahan Atas Keputusan Menteri Kelautan dan Perikanan. 
Koentjaraningrat. 2009: Manusia dan Kebudayaan di Indonesia. Djambangan. Jakarta. Longman.

Neufert, Ernest. 1936. Data Arsitek Jilid 2. Terjemahan oleh Sunerto Tjahjadi. 2002. Jakarta: Erlangga.

Neufert, Ernst. 1936. Neufret Architec's Data Third Edition. Diedit oleh Bousmaha Baiche dan Nicholas Walliman.UK: Blackwell Science.

Primadella, dan Ikaputra. (2019). Waterfront culture sebagai atraksi wisata tepian air. Jurnal Arsitektur ZONASI, 2(2), 88-97.

Sipahelut, Michel. 2010. Analisis Pemberdayaan Masyarakat Nelayan Di Kecamatan Tobelo Kabupaten Halmahera Utara. Tesis. IPB. Bogor.

Tisnawati, E., Natalia, D. A., Ratriningsih, D., Putro, A. R., Wirasmoyo, W., Brotoatmodjo, H. P., \& Asyifa, A. (2019). Strategi Pengembangan Eko-Wisata Berbasis Masyarakat di Kampung Wisata Rejowinangun. INERSIA, 13(2), 1-11. doi:https://doi.org/10.21831/inersia.v15i1.24859.

UU RI no. 10 th 2009 Tentang Pariwisata. 